\title{
Spatiotemporal Differentiation of Coupling and Coordination Relationship of the Tea Industry-Tourism-Ecological Environment System in Fujian Province, China
}

\author{
Qian Cheng ${ }^{1}$, Zhongheng Luo ${ }^{1}$ and Ling Xiang ${ }^{1,2, *}$ \\ 1 School of Tourism and Urban Rural Planning, Zhejiang Gongshang University, Hangzhou 310018, China; \\ huyangstone@mail.zjgsu.edu.cn (Q.C.); $20010060001 @$ pop.zjgsu.edu.cn (Z.L.) \\ 2 School of Foreign Languages, Zhejiang Gongshang University, Hangzhou 310018, China \\ * Correspondence: friedaxiang@zjgsu.edu.cn
}

\section{check for}

updates

Citation: Cheng, Q.; Luo, Z.; Xiang, L. Spatiotemporal Differentiation of Coupling and Coordination Relationship of the Tea Industry-Tourism-Ecological Environment System in Fujian Province, China. Sustainability 2021, 13, 10628. https://doi.org/10.3390/ su131910628

Academic Editors: João Romão and Yahua Bi

Received: 21 August 2021

Accepted: 22 September 2021

Published: 24 September 2021

Publisher's Note: MDPI stays neutral with regard to jurisdictional claims in published maps and institutional affiliations.

Copyright: (c) 2021 by the authors. Licensee MDPI, Basel, Switzerland. This article is an open access article distributed under the terms and conditions of the Creative Commons Attribution (CC BY) license (https:/ / creativecommons.org/licenses/by/ $4.0 /)$.

\begin{abstract}
Correctly understanding and handling the relationships in the tea industry-tourismecological environment system is a prerequisite and foundation for the high-quality and sustainable development of the tea tourism industry. In this study, an evaluation index system of the tea industrytourism-ecological environment system is established, the weight coefficient of each indicator is determined by the entropy weight method, and the coupling coordination degrees of Fujian Province and nine cities therein are evaluated by constructing a coupling coordination model from 2011 to 2019. The results indicate that the comprehensive development index of the tea industry-tourismecological environment system had an overall upward trend from 2011 to 2019, and the coupling coordination degree of the three systems changed from moderate maladjustment to high-quality coordination. There was spatial heterogeneity in the comprehensive development indices and coupling coordination degrees of the three systems, when considering the nine cities of Fujian Province. This study offers both theoretical and practical implications for further improving the development level and overall coordination between the tea industry, tourism, and the ecological environment in Fujian province.
\end{abstract}

Keywords: tea industry; tourism industry; ecological environment; coupling coordination; Fujian province

\section{Introduction}

China is a traditional tea-producing country and the birthplace of tea culture, being the country with the largest scale of tea planting and the largest output of tea in the world [1,2]. As such, the tea industry is of great significance in optimizing the rural industrial structure, improving the ecological environment, and promoting rural economic prosperity and the development of urban and rural integration [3]. Compared with other tea-producing countries in the world, tea production efficiency and added value are not high in China, and the deep processing of tea products needs to be improved $[4,5]$. On the one hand, from the perspective of market demand, the domestic tea demand market changes rapidly; according to data from the China Tea Marketing Association, China's tea output was 2.772 million tons, while the total domestic sales amounted to 2.0256 million tons in 2019. As such, the gap between the output and sales has led to a continuous increase in inventory [6]. On the other hand, the consumption demand of individuals has changed from material consumption demand to experience and spiritual consumption demand. IIMedia research data has shown that $27.6 \%$ of Chinese consumers drink tea mainly for leisure and relaxation, while $18.5 \%$ of consumers drink tea for refreshment and other material consumption [7]. The integration of tea tourism can provide development space for improving the efficiency of the tea industry [8], and the different production links of the tea industry can be continuously integrated into the six consumption factors of tourism, in order to form a new tea tourism based on economic consumption, such as manor 
experiences, tea garden festivals, cultural performances, and tea cultural and creative souvenirs $[9,10]$. In recent years, with the promotion of the concept of "tea + tourism", tea culture tourism has become popular and tea culture tourism products have been developed in various tea-producing areas, which can increase the income of tea industry practitioners and promote the development of the tourism economy [11]. Many studies have proved that the integrated development of the tea industry and tourism has become an important way to extend the industrial chain of agricultural products and to promote the innovation of the format of the tea industry, and can contribute to product innovation and tea culture protection $[7,12]$.

The ecological environment is an important condition for tea production, and is also the basis for the sustainable development of tea. Tea planting has ecological functions and advantages, such as conserving water and soil, greening the environment, maintaining biodiversity, and improving the living environment [13]; however, the excessive use of pesticides in tea production causes damage to the environment $[14,15]$. On the other hand, climate change and environmental problems caused by carbon emissions are prominent weaknesses in the construction of ecological civilization. The tourism industry is one of the important sources of carbon emissions, and its "smoke-free industry" has been denied by most studies [16,17]. At present, as the integration level of the tea industry and tourism is still relatively low $[1,11,12,18]$, there are many phenomena, such as the disordered development of tea and tourism resources, extensive development of the tea tourism industry, and overloaded operations of tea tourism destinations, which have aggravated the ecological environment's burden, to a certain extent, thus causing many environmental problems. Environmental degradation increases the cost of economic activities and restricts the sustainable development of the tea tourism industry after breaking through its threshold value. Zhang et al. have proposed that the development of low-carbon tea culture tourism is an important measure to realize the symbiotic development of the original ecology and tea tourism economy in tea-producing areas [19].

A coupling coordination relationship refers to the interaction and mutual influence between two or more systems based on a specific connection [20]; the coupling relationship between systems or elements will evolve with time, resulting in the evolution from disharmony to coordination [21,22]. The tea industry-tourism-ecological environment system has a significant impact on regional economic development, and there are significant correlations and interactions among the two. Existing research has mainly focused on the relationship between the tea industry and tourism [23-25], or the relationship between tourism and ecological environment [26-29]. There is a limited number of studies which have integrated the three systems into the same research framework, and few scholars have conducted quantitative research on the coupling relationships of the three systems. Zhang proposed that tea culture and tourism have an interdependent and mutually promoting relationship; at the same time, the development of tea culture tourism is expected to pollute the air, land, and water sources of the destination [30]. Xu also discussed the relationship between tea culture, tourism, and the ecological environment, showing that tea culture can promote the cultural value of tourism and bring aesthetic experiences to tourists [31]. However, if there is no overall planning for the development of tea culture tourism, it may increase carbon emissions and pollute the environment. At present, research on the relationships between the tea industry, tourism, and the ecological environment has mainly adopted qualitative and empirical description methods and lacks specific quantitative analyses. In other words, existing studies in the literature generally have not paid attention to the ecological damage caused by tea tourism integration and the protection function of the tea industry to tourism and the environment. Most studies on the integration of the tea industry and tourism have focused on time dimension analysis [23-25,32], without discussing the spatial changes and differences of the coupling and coordination degree of the internal units in the region. The tea industry provides more resources for tourism, while tourism promotes the transformation and upgrading of the tea industry [12]; however, the integration of the tea industry and tourism imposes a burden on the ecological environ- 
ment, which is the basis for the sustainable development of the tea industry and tourism. Therefore, realizing the coupling and coordinated development of the tea industry-tourismenvironment is the key to the high-quality and sustainable development of the tea tourism industry; as such, it is of great theoretical and practical significance to study the coupling relationship of the three systems.

To address the gaps mentioned above, it is necessary to use multiple methods to solve the above problems. Constructing an overall evaluation index system is a prerequisite for effectively evaluating the comprehensive development level of the three sub-systems, and the entropy weight method can determine the weight coefficient of each index according to the information contained in each index, which is a more objective method [33]. In this study, taking Fujian Province as an example, we construct an index evaluation system for the tea industry-tourism-ecological environment coupling coordination, and measure the coupling coordination level of the tea industry-tourism-ecological environment system in Fujian Province from 2011 to 2019. At the same time, from a spatial perspective, we analyze the coupling and coordination evolution trends of the tea industry-tourism-ecological environment system in nine cities of Fujian Province, in order to provide reference and guidance for the development of the tea tourism industry and ecological civilization construction in Fujian Province.

\section{Literature Review}

\subsection{Tea Industry and Tourism Integration}

As a new type of business, the tea tourism industry has been widely considered by scholars. Due to the particularity of the tea industry, the tea industry and related research have been mainly concentrated in China, and there is very little literature on tea tourism published in English [34]. The existing research on the integration and interaction of the tea tourism industry has mainly focused on the status, significance, path, and coupling level measurement of the tea tourism industry. Firstly, scholars have carried out detailed studies on the concept and content of the tea tourism industry. Jolliffe defined tea tourism as "tourism that is motivated by an interest in the history, traditions and consumption of tea" [35]. Keunuk proposed that tea culture tourism is a new tourism format, integrating tourism and modern agriculture [36]. Wang et al. held that the tea tourism industry is a series of tourism activities with various forms and rich content, which takes tea and tea culture as the theme [37]. Lin et al. stated that tea tourism takes tea and tea culture as the core resources, including tea discovery, tea history, tea production, tea customs, tea-drinking art, tea ceremonies, and other activities [38]. Generally speaking, the definition of tea tourism can be summarized as tourism activities with tea and tea culture as the core.

The second aspect that scholars have discussed involves the significance of tea tourism integration. Gao et al. presented that the integration of tea and tourism is conducive to increasing the added value of the tea industry, extending the tourism industry chain [39]. Zhang suggested that the integration of tea and tourism is of great significance to the development of tourism and is of practical significance to solving the homogenization of the tea industry, developing rural tourism, and enabling rural revitalization [40]. Anxi county is a green tea-producing county in Fujian Province. Through the development of tea culture tourism, Anxi county received 8.4892 million domestic and foreign tourists in 2019, comprising an increase of $10.7 \%$, and the total tourism revenue was 11.113 billion yuan, an increase of $18.8 \%$ [41]. The integration of the tea industry and tourism has promoted the transformation and upgrading of the rural economy and the improvement of income in Anxi county.

The third aspect is the level measurement of tea tourism integration. Ji et al. found that the production, planting, processing, and sales associated with the tea industry in Anxi county are coupled with the six elements of food, housing, transportation, travel, shopping, and entertainment in different degrees [9]. Guo et al. argued that the integration of tea and tourism in southern Shaanxi has shifted from an extreme imbalance to intermediate imbalance [42]. Based on the data for the tea tourism industry in Anhui Province from 
2003 to 2016, Wu et al. presented that the tea tourism industry in Anhui Province has changed from a serious imbalance to primary coordination [11]. Yi et al. have constructed a motivation, path, and benefit model of tea tourism industry integration in Zhejiang Province and showed that the tea industry plays a leading role in the tourism industry in Zhejiang Province [12]. Based on the panel data of eight provinces, Wang suggested that the integration of tea tourism in Jiangxi and the other eight provinces differed, and the advantages of tourism and the tea industry are different in different provinces [18].

The fourth aspect involves the countermeasures and suggestions of tea tourism integration. Hou et al. took Longsheng Autonomous County of Guangxi as an example and proposed that tea tourism integration should be promoted considering the aspects of industry penetration, product supply, factor restructuring, demand-driven, process experience, and so on [43]. Pang et al. proposed that the government should play a leading role in the integration of tea tourism in Sichuan Province, improve the comprehensive level of the tea tourism industry, and create special tourism routes for tea tourism [44].

Through the above analysis, it can be found that the integration of tea and tourism is at a relatively low level in each province, and there exists spatial heterogeneity in the integration level of tea and tourism. At the same time, previous studies were mainly based on provincial panel data analysis, only measuring the provincial coupling level from the time sequence, and not the spatial coupling structure evolution of tea tourism integration in the city unit from the perspective of the spatiotemporal dual structure.

\subsection{The Relationships in the Tea Industry-Tourism-Ecological Environment System}

The tea industry-tourism-ecological environment system constitutes a circulation system of mutual coordination, mutual promotion, and mutual restriction. Firstly, there is an organic interactive relationship between the tea industry and tourism integration $[9,12]$. With the development of China's tea industry and tourism, the integration and interaction of tea planting, tea production, processing, selling, and tourism are becoming increasingly closer $[9,45]$. Tea trees, tea gardens, tea farms, tea sets, tea ceremonies, tea poems, tea paintings, tea houses, and so on constitute a unique attraction for tea culture tourism, which can meet the diversified tourism needs of tourists, such as leisure, sightseeing, vacationing, research, shopping, and health [3,35], such that tourism guides tourists to enter tea gardens to experience sightseeing, promote tea garden consumption, and realize capital flow. At the same time, tea tourism integration can further promote innovation in the tea tourism industry [12].

Secondly, the ecological environment is the bottom line and foundation of the development of the tea tourism industry. On the one hand, the ecological environment is the basis for the development of tourism, providing sufficient natural resources and material guarantees for the tourism industry [46]. The development of the tourism industry relies on the ecological environment and climatic conditions [47]. On the other hand, the tea plant and growth depend largely on the natural conditions, such as light, water, soil, and temperature [31]. The suitable temperature for tea tree planting shall be between 20 and $30{ }^{\circ} \mathrm{C}$ [48]. To plant tea in an ecological tea garden system, the soil maturation layer needs to be greater than $50 \mathrm{~cm}$, and the moisture content of the soil shall be around 23-34\%, while the shading rate of the plant protection fence also needs to be controlled within 30\% [49]. At the same time, tea is not only considered as an economic crop, but also an evergreen herb, which has many ecological and environmental functions, such as regulating the microclimate of the tea garden, generating organic matter, absorbing carbon dioxide, and improving soil fertility [50]. According to the research, China's tea plants can absorb about $26.0 \mathrm{t} / \mathrm{hm}^{2}$ of carbon dioxide in the air every year through photosynthesis, and the yield of organic organisms can reach about $14.0 \mathrm{t} / \mathrm{hm}^{2}$ every year. The tea litter falling into the land can effectively increase the soil's organic carbon at $690-1380 \mathrm{~kg} / \mathrm{hm}^{2}$ every year [51].

Thirdly, the tourism industry would generate tremendous carbon emissions during the development process, which would largely result in environmental degradation, climate warming, and many other ecological and environmental issues. At the same time, in the 
process of developing the tea industry, if a large number of pesticides and fertilizers are used, damage to the ecological environment will result [14,15]. However, the development of the tea industry and tourism can promote economic development, and the spillover effect of economic development has a positive effect on the construction of the ecological environment. It may help to promote the optimization of the tourism industry structure, improve the ecological environment infrastructure, generate more fund for pollution control, and boost ecological environment quality improvement [52].

In summary, current domestic and foreign studies on the integration of the tea industry and tourism have mainly focused on the conceptual connotation $[35,36]$, path mechanism $[43,44]$, and the level of coupling and coordination $[9,12,18]$. Previous studies have mainly studied the coupling and coordination relationship between the tea industry and the tourism industry [39], but did not pay attention to the impact of tea and tourism integration on the ecological environment system. Therefore, establishment of the relationships between the tea industry, tourism, and the ecological environment can provide a useful supplement to the previous research on the coupling relationship between the tea industry and the tourism industry. Quantitative evaluation of the coupling and coordination degree of the three systems can provide specific guiding measures and directions for environmental protection.

\section{Research Design and Data Sources}

\subsection{Study Area}

Fujian Province is located on the southeast coast of China (see Figure 1). It is the starting point of the Wanli tea ceremony, and tea is one of the most widely distributed economic crops in Fujian. It has a superior natural and economic environment for tea planting, production, processing, and trade, and has a long history of tea planting. In 2019, Fujian's tea output reached 439,900 tons. The tea output was 461,000 tons in 2020, and the growth rate of tea production was $4.8 \%$ in 2020. Nine cities have tea plantations in Fujian Province; in 2019, Ningde had the highest tea output, reaching 104,300 tons and accounting for $23.71 \%$ of the total output of Fujian Province. Quanzhou and Nanping ranked second and third, with outputs of 87,100 tons and 75,500 tons, respectively, accounting for $19.81 \%$ and $17.17 \%$ of the total output of Fujian Province [53]. At present, Quanzhou, Nanping, and Putian are the main production areas for oolong tea, Ningde is the main production area for black and green tea, Fuzhou is the main production area for white tea, and Sanming is a production area for various types of tea. At the same time, with tea as the medium, Fujian continues to promote the integration of tea and tourism and has formed a new business form of tea and tourism integration, including Dahongpao tea tourism performance, Anxi ecological sightseeing tea manor, and so on. Taking Fujian Province as the research object, we analyzed the coupling and coordination relationships between the tea industry, tourism, and the ecological environment.

\subsection{Evaluation Index System Construction}

We constructed an evaluation index system for the tea industry, tourism, and ecological environment, which is mainly based on the three criteria of scientificity, effectiveness, and availability of evaluation indices [54,55]. A variety of methods were used to establish the evaluation index system. After reviewing the literature on the coupling coordination between the tea industry, tourism, and the ecological environment, combined with the actual situation of industry, tourism, and the ecological environment in Fujian Province, a coupling coordination evaluation index system of the tea industry, tourism, and the ecological environment of Fujian Province was systematically constructed (Table 1). On the basis of referring to the existing literature on the coupling coordination between the tea industry and tourism [12,18], and that for the tourism industry and the ecological environment [56-58], combined with the advice of experts, we determined that efficiency is an important factor in evaluating a system. In the system, the tea industry indices comprise six elements, including tea industry scale and tea efficiency, and the tourism industry 
indices comprise six elements, including tourism scale and tourism efficiency. Finally, the ecological environment indices comprise nine elements, including environmental pollution and environmental governance.

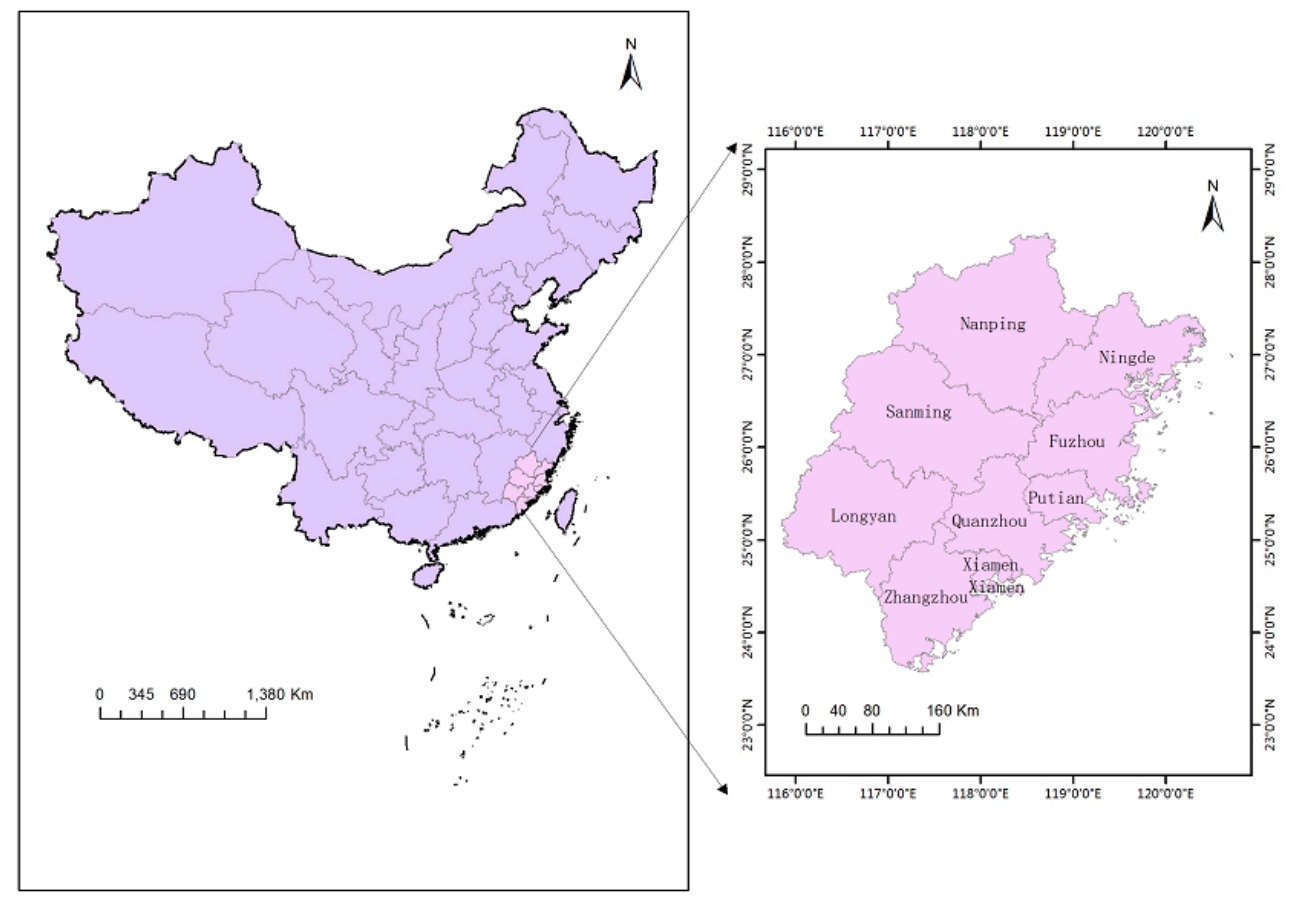

Figure 1. Map of Fujian Province.

\subsection{Research Methods}

Coupling coordination degree is an important index to evaluate the interaction development level of multiple systems [20]. Previous studies have evaluated the internal development relationship of multiple systems by building a coupling coordinated model, which is widely used in the fields of ecological environment, tourism industry, and urbanization, which is an important model for studying economy, environment, industry and tourism [12,18,57,58]. Tea industry, tourism, and the ecological environment constitute a complex dynamic system; the comprehensive development level index and coupling coordination degree can clearly judge the development level differences and internal interaction relationships between the tea industry, tourism, and the ecological environment at different time points. This paper also evaluates the interactive development relationship between the tea industry, tourism, and the ecological environment system based on the coupling coordination model method.

\subsubsection{Entropy Weight Method}

To measure the development level of the tea industry-tourism-ecological environment system, it was necessary to determine the weight of each indicator. Compared with the AHP method, the entropy weight method is more objective when determining weights based on the information contained in each indicator [33,59]. In this study, the data of Fujian Province were selected to calculate the weights using the entropy weight method. The results are shown in Table 1. The specific calculation steps are as follows: 
Table 1. The evaluation index system of tea industry-tourism-ecological environment coupling coordination.

\begin{tabular}{|c|c|c|c|c|}
\hline First Level Indicators & Second Level Indicators & Third Level Indicators & Nature & Weight \\
\hline \multirow{5}{*}{$\begin{array}{l}\text { Tea industry } \\
\text { development }\end{array}$} & \multirow{2}{*}{ Tea industry scale } & Tea planting area $(\mathrm{mu})$ & + & 0.1509 \\
\hline & & Tea production (ton) & + & 0.1959 \\
\hline & \multirow{3}{*}{ Tea industry efficiency } & Tea area per capita (mu/10,000 people) & + & 0.1432 \\
\hline & & $\begin{array}{c}\text { Tea production per capita (tons } / 10.000 \\
\text { people) }\end{array}$ & + & 0.1891 \\
\hline & & $\begin{array}{c}\text { The proportion of tea planting area in crop } \\
\text { planting }(\%)\end{array}$ & + & 0.1413 \\
\hline \multirow{7}{*}{$\begin{array}{l}\text { Tourism industry } \\
\text { development }\end{array}$} & \multirow{5}{*}{ Tourism industry scale } & $\begin{array}{l}\text { The proportion of tea production in grain } \\
\text { production }(\%)\end{array}$ & + & 0.1795 \\
\hline & & Inbound tourism revenue $(1,000,000,000$ yuan $)$ & + & 0.1647 \\
\hline & & Domestic tourism revenue $(10,000$ USD) & + & 0.2023 \\
\hline & & Domestic tourists $(10,000$ people $)$ & + & 0.1664 \\
\hline & & Number of inbound tourists (people) & + & 0.1524 \\
\hline & Tourism industry efficiency & $\begin{array}{c}\text { The proportion of inbound tourism revenue in } \\
\text { the tertiary industry }(\%)\end{array}$ & + & 0.1403 \\
\hline & & $\begin{array}{l}\text { The proportion of domestic tourism revenue } \\
\text { in the tertiary industry }(\%)\end{array}$ & + & 0.1740 \\
\hline \multirow{9}{*}{ Ecological environment } & \multirow{5}{*}{ Environmental pollution } & $\begin{array}{c}\text { The output of industrial solid waste }(10,000 \\
\text { tons) }\end{array}$ & - & 0.0743 \\
\hline & & Sulfur dioxide emissions (ton) & - & 0.1791 \\
\hline & & Emission of smoke and dust (ton) & - & 0.0811 \\
\hline & & Wastewater discharge ( 10,000 tons $)$ & - & 0.1006 \\
\hline & & Sewage treatment rate $(\%)$ & + & 0.1211 \\
\hline & \multirow{4}{*}{ Environmental governance } & Green coverage area (hectare) & + & 0.0888 \\
\hline & & $\begin{array}{l}\text { Harmless treatment rate of domestic waste } \\
\qquad(\%)\end{array}$ & + & 0.0614 \\
\hline & & Green coverage of built-up area (\%) & + & 0.0832 \\
\hline & & $\begin{array}{c}\text { Comprehensive utilization of industrial solid } \\
\text { waste (10,000 tons) }\end{array}$ & + & 0.2105 \\
\hline
\end{tabular}

(1) First, the original data were standardized by the range method, in order to eliminate the order of magnitude and dimension. To eliminate the phenomenon of zero value after the original data standardization, the standardized value was processed by adding 0.01 :

$$
\begin{gathered}
\text { Positive indicators: } X_{i j}^{\prime}=\frac{\left(X_{i j}-\min X_{i}\right)}{\left(\max X_{i}-\min X_{i}\right)}+0.01, \\
\text { Negative indicators: } X_{i j}^{\prime}=\frac{\left(\max X_{i j}-X_{i j}\right)}{\left(\max X_{i j}-\min X_{i j}\right)}+0.01 \text {. }
\end{gathered}
$$

(2) Calculation of indicators' proportion:

$$
Y_{i j}=\frac{X_{i j}^{\prime}}{\sum_{i=1}^{n} X_{i j}^{\prime}}
$$

(3) Calculation of information entropy:

$$
E_{j}=-\frac{1}{\ln n} \sum_{i=1}^{n} Y_{i j} \ln Y_{i j}
$$

(4) Calculation of difference coefficient:

$$
H_{j}=1-E_{j} .
$$

(5) Determination of indicator weights:

$$
W_{j}=H_{j} / \sum_{j=1}^{m} H_{j}=\left(1-E_{j}\right) /\left(n-\sum_{j=1}^{m} E_{j}\right) .
$$




\subsubsection{Calculation of Comprehensive Development Index}

The comprehensive development index (CDI) of the tea industry-tourism-ecological environment sub-systems, as well as the overall comprehensive development index, were further evaluated using the value and weight of each indicator after standardized treatment:

$$
C D I_{j}=\sum_{i=1}^{n} W_{j} X_{i j}^{\prime} T=\alpha \times C D I_{1}+\beta \times C D I_{2}+\gamma \times C D I_{3},
$$

where $C D I_{j}$ is the comprehensive development index of sub-system $j, W_{j}$ is the weight coefficient of the $j$ th indicator, $T$ is the overall comprehensive development index of the three major systems, and $\alpha, \beta$, and $\gamma$ represent the coefficients for the tea industry, tourism, and the ecological environment, respectively. As the ecological environment plays a fundamental and decisive role, it is the bottom line of tea tourism industry development. Therefore, according to expert opinions, and referring to the existing research conclusions $[46,60]$, $\alpha$ and $\beta$ were set as 0.3 , while $\gamma$ was set as 0.4 .

\subsubsection{Coupling Coordination Model}

Based on the theory of coupling and coordinated development, and referring to the research of Liu et al $[46,58,60]$, the coupling model of the tea industry-tourism-ecological environment system was constructed as follows:

$$
C=\sqrt[3]{\frac{C D I_{1} \times C D I_{2} \times C D I_{3}}{\left\{\left(C D I_{1}+C D I_{2}+C D I_{3}\right) / 3\right\}^{3}}},
$$

where $C$ is the coupling degree, which indicates the interaction and influence degree of the three sub-systems, with value in the range $[0,1.01]$. When $C=0$, it indicates that the three systems are in an independent state. When $C=1.01$, it indicates that the three systems are in an optimal coupling resonance state. As the coupling degree can only reflect the degree of interaction between the systems, and cannot reflect the real level of coordination, the coupling coordination model is introduced to better evaluate the coupling coordination degree between the tea industry-tourism-ecological environment system:

$$
D=\sqrt{(C \times T)},
$$

where $D$ is the coupling coordination degree of the tea industry-tourism-ecological environment system, $C$ is the coupling degree, and $T$ is the overall comprehensive development index of the tea industry-tourism-ecological environment system. The division standard

\begin{tabular}{|c|c|c|c|}
\hline C Value & Stage & D Value & Type \\
\hline \multirow{3}{*}{$0 \leq \mathrm{C} \leq 0.3$} & \multirow{3}{*}{ Low-level coupling } & $0.00<\mathrm{D} \leq 0.10$ & Extreme maladjustment \\
\hline & & $0.10<\mathrm{D} \leq 0.20$ & Serious maladjustment \\
\hline & & $0.20<\mathrm{D} \leq 0.30$ & $\begin{array}{c}\text { Moderate } \\
\text { maladjustment }\end{array}$ \\
\hline \multirow{2}{*}{$0.3<\mathrm{C} \leq 0.5$} & \multirow{2}{*}{ Antagonistic stage } & $0.30<\mathrm{D} \leq 0.40$ & Mild maladjustment \\
\hline & & $0.40<\mathrm{D} \leq 0.50$ & $\begin{array}{l}\text { On the verge of } \\
\text { maladjustment }\end{array}$ \\
\hline \multirow{3}{*}{$0.5<\mathrm{C} \leq 0.8$} & \multirow{3}{*}{ Running in stage } & $0.50<\mathrm{D} \leq 0.60$ & Grudging coordination \\
\hline & & $0.60<\mathrm{D} \leq 0.70$ & Primary coordination \\
\hline & & $0.70<\mathrm{D} \leq 0.80$ & $\begin{array}{l}\text { Intermediate } \\
\text { coordination }\end{array}$ \\
\hline \multirow{2}{*}{$0.8<\mathrm{C} \leq 1$} & \multirow{2}{*}{ High-level coupling } & $0.80<\mathrm{D} \leq 0.90$ & Good coordination \\
\hline & & $0.90<\mathrm{D} \leq 1.00$ & $\begin{array}{l}\text { High-quality } \\
\text { coordination }\end{array}$ \\
\hline
\end{tabular}
for the coupling coordination degree is shown in Table 2.

Table 2. Measurement standard and classification type of coupling coordination degree. 


\subsubsection{Data Sources}

The output of tea in Fujian Province was 277,000 tons in 2011 and 439,900 tons in 2019 , with a growth rate of $58.81 \%$; meanwhile, the number of domestic tourists in Fujian Province in 2011 was 142.3 million, and the domestic tourism revenue reached 144.4 billion yuan. In contrast, the number of domestic tourists in 2019 was 526.97 million, and the domestic tourism revenue reached 739.3 billion yuan [53]. From 2011 to 2019, tea planting in Fujian Province continued to expand and the number of tourists increased rapidly. Based on the availability of data, we took 2011-2019 as the research time sequence and took Fujian Province and nine cities as the research samples, in order to reflect the changes in the tea industry, tourism, and the ecological environment. The relevant indicators of the tea industry, tourism, and the ecological environment were derived from the 2011-2019 Fujian Statistical Yearbook and the China Tourism Statistical Yearbook, the China Environment Statistical Yearbook, the local Statistical Yearbooks of cities, and local Statistical Bulletins of 2011-2019.

\section{Result Analysis}

\subsection{Comprehensive Development Index and Coupling Coordination Degree Analysis in Fujian Province}

Based on the comprehensive development index and coupling coordination model, the comprehensive development index of each sub-system $\left(\mathrm{CDI}_{1}, \mathrm{CDI}_{2}\right.$, and $\left.\mathrm{CDI}_{3}\right)$, the total comprehensive development index (T), coupling degree (C), and coordination degree (D) of the three sub-systems were calculated, using the entropy weight method, for 2011-2019. The data research results (see Figure 2 and Table 3) showed that the total comprehensive development index of the tea industry-tourism-ecological environment system showed an upward trend in Fujian Province from 2011 to 2019: as time progressed, the comprehensive development index reached 0.85 in 2019, and the overall development level of the three systems indicated a good development state. However, the comprehensive development index of the tea industry-tourism-ecological environment system had the characteristics of cross-alternating forward. In 2011, the comprehensive development index of the tea industry was low, and the comprehensive development index of the ecological environment was the highest; at this stage, the tea industry lagged behind the development of the tourism industry and ecological environment, and the ecological environment was in a good development state. The main reason for this is that the scale of tea production in Fujian Province was small in 2011, while the tourism industry was still in the exploratory development stage and its development efficiency was low [61]. From 2012 to 2017, the comprehensive development index of the tourism industry was low, and the comprehensive development index of the tea industry and ecological environment took the lead alternately. At this stage, the tourism industry lagged behind the development of the tea industry and the ecological environment. The tea industry played a leading role in the tourism industry, and the ecological environment began to show a fluctuating development trend. The reason for this is that the integration of the tea industry and tourism led to disturbances to the ecological environment, mainly due to the disorderly and blind tea tourism industry development, leading to wasted resources and environmental damage [62]. In 2018 and 2019, the development index of the ecological environment was low, and the development index of the tea industry was the highest. At this stage, the ecological environment lagged behind the development of tea industry and tourism, the reason being that the deep integration of the tea industry and tourism led to negative impacts on the ecological environment, mainly reflected in the use of non-environmental protection products in the hotel and catering industry. At the same time, a large number of tourists visited tea gardens, who lacked environmental protection awareness during sightseeing [31].

Aside from the coupling degree of the three systems being low in 2011, the coupling degree of the three systems was more than 0.9 from 2012 to 2019 and, so, the three systems were in a high-level coupling state. The coordination degree generally presented an upward ladder trend, from serious maladjustment in 2011 to high-quality coordination in 2019. 
4.2. Comprehensive Development Index and Coupling Degree Analysis in Nine Cities of Fujian Province

Through the evaluation of the tea industry-tourism-ecological environment comprehensive development index and coupling degree of nine cities in Fujian Province from 2011 to 2019 (Table 4 and Figure 3), it was found that the comprehensive development index of the three sub-systems in nine cities showed a trend of growth; however, the tea industry development indices of Putian, Xiamen, and Zhangzhou showed a downward trend from 2017 to 2018, mainly due to the impact of adjustment of the agricultural product planting structure and extremely bad weather. The average coupling degree of the three sub-systems of the nine cities in Fujian Province was generally high from 2011 to 2019, where the average coupling degree was above 0.8 . This indicates that the three sub-systems of the nine cities were consistent with the overall development trend from 2011 to 2019.

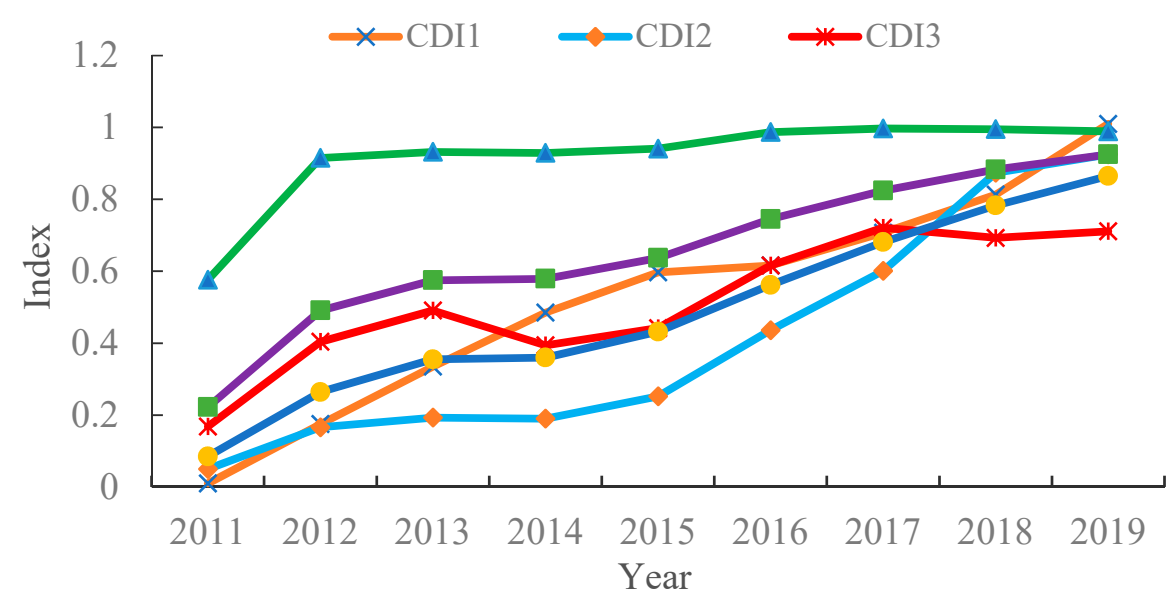

Figure 2. Comprehensive development index and coupling coordination degree curves for the tea industry-tourism-ecological environment system in Fujian Province from 2011 to 2019.

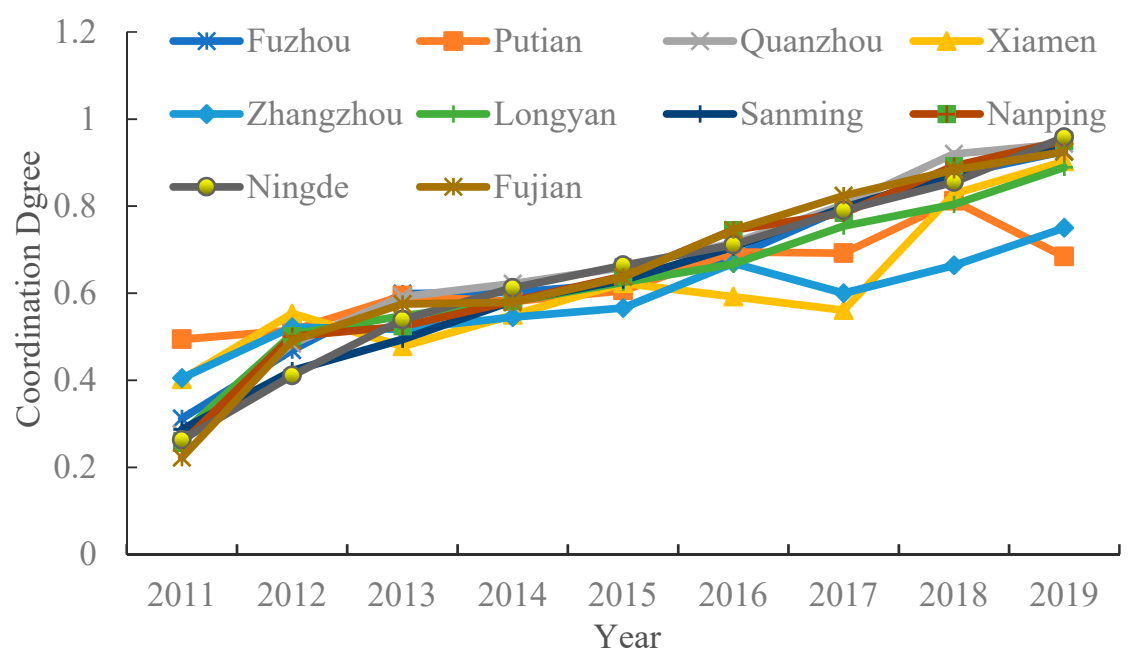

Figure 3. Coupling coordination degree curves of the tea industry-tourism-ecological environment systems for various cities in Fujian province from 2011 to 2019. 
Table 3. Comprehensive development index and coupling coordination degree of the tea industry-tourism-ecological environment system in Fujian Province from 2011 to 2019.

\begin{tabular}{|c|c|c|c|c|c|c|c|}
\hline Year & $\mathrm{CDI}_{1}$ & $\mathrm{CDI}_{2}$ & $\mathrm{CDI}_{3}$ & $\mathrm{~T}$ & C & D & $\begin{array}{c}\text { Classification of } \\
\text { type }\end{array}$ \\
\hline 2011 & 0.010 & 0.050 & 0.168 & 0.085 & 0.576 & 0.222 & $\begin{array}{l}\mathrm{CDI}_{1} \text { lagging, } \\
\mathrm{CDI}_{3} \text { leading }\end{array}$ \\
\hline 2012 & 0.175 & 0.166 & 0.404 & 0.264 & 0.915 & 0.491 & $\begin{array}{l}\mathrm{CDI}_{2} \text { lagging, } \\
\mathrm{CDI}_{3} \text { leading }\end{array}$ \\
\hline 2013 & 0.335 & 0.193 & 0.491 & 0.355 & 0.932 & 0.575 & $\begin{array}{l}\mathrm{CDI}_{2} \text { lagging, } \\
\mathrm{CDI}_{3} \text { leading }\end{array}$ \\
\hline 2014 & 0.485 & 0.190 & 0.394 & 0.360 & 0.929 & 0.579 & $\begin{array}{l}\mathrm{CDI}_{2} \text { lagging, } \\
\mathrm{CDI}_{1} \text { leading }\end{array}$ \\
\hline 2015 & 0.597 & 0.252 & 0.442 & 0.432 & 0.941 & 0.637 & $\begin{array}{l}\mathrm{CDI}_{2} \text { lagging, } \\
\mathrm{CDI}_{1} \text { leading }\end{array}$ \\
\hline 2016 & 0.616 & 0.436 & 0.616 & 0.562 & 0.987 & 0.745 & $\begin{array}{l}\mathrm{CDI}_{2} \text { lagging, } \\
\mathrm{CDI}_{3} \text { leading }\end{array}$ \\
\hline 2017 & 0.707 & 0.601 & 0.721 & 0.681 & 0.997 & 0.824 & $\begin{array}{l}\mathrm{CDI}_{2} \text { lagging, } \\
\mathrm{CDI}_{3} \text { leading }\end{array}$ \\
\hline 2018 & 0.813 & 0.874 & 0.693 & 0.783 & 0.995 & 0.883 & $\begin{array}{l}\mathrm{CDI}_{3} \text { lagging, } \\
\mathrm{CDI}_{1} \text { leading }\end{array}$ \\
\hline 2019 & 1.010 & 0.925 & 0.711 & 0.865 & 0.989 & 0.925 & $\begin{array}{l}\mathrm{CDI}_{3} \text { lagging, } \\
\mathrm{CDI}_{1} \text { leading }\end{array}$ \\
\hline
\end{tabular}

$\mathrm{CDI}_{1}$ represents the comprehensive development level of the tea industry, $\mathrm{CDI}_{2}$ represents the comprehensive development level of the tourism industry, $\mathrm{CDI}_{3}$ represents the comprehensive development level of the ecological environment, $\mathrm{T}$ represents the overall comprehensive development level of the tea industry-tourism-ecological environment system, C represents the coupling degree, and D represents the coordination degree.

Table 4. Comprehensive development index and coupling degree of tea industry-tourism-ecological environment systems in various cities of Fujian province from 2011 to 2019.

\begin{tabular}{|c|c|c|c|c|c|c|c|c|c|c|c|}
\hline Item & City & 2011 & 2012 & 2013 & 2014 & 2015 & 2016 & 2017 & 2018 & 2019 & Mean \\
\hline \multirow{9}{*}{$\mathrm{CDI}_{1}$} & Fuzhou & 0.010 & 0.098 & 0.380 & 0.404 & 0.490 & 0.577 & 0.811 & 0.877 & 0.938 & 0.510 \\
\hline & Putian & 0.282 & 0.480 & 0.571 & 0.707 & 0.866 & 0.972 & 0.255 & 0.486 & 0.129 & 0.527 \\
\hline & Quanzhou & 0.001 & 0.180 & 0.366 & 0.498 & 0.624 & 0.691 & 0.725 & 0.909 & 0.958 & 0.553 \\
\hline & Xiamen & 0.348 & 0.351 & 0.339 & 0.424 & 0.388 & 0.151 & 0.067 & 0.526 & 0.090 & 0.388 \\
\hline & Zhangzhou & 0.448 & 0.528 & 0.642 & 0.665 & 0.445 & 0.574 & 0.147 & 0.254 & 0.386 & 0.455 \\
\hline & Longyan & 0.211 & 0.538 & 0.653 & 0.792 & 0.897 & 0.377 & 0.466 & 0.482 & 0.648 & 0.563 \\
\hline & Sanming & 0.139 & 0.271 & 0.378 & 0.475 & 0.598 & 0.470 & 0.587 & 0.613 & 0.728 & 0.473 \\
\hline & Nanping & 0.017 & 0.192 & 0.354 & 0.607 & 0.733 & 0.809 & 0.518 & 0.724 & 0.834 & 0.543 \\
\hline & Ningde & 0.010 & 0.223 & 0.244 & 0.361 & 0.502 & 0.541 & 0.643 & 0.642 & 1.010 & 0.474 \\
\hline \multirow{9}{*}{$\mathrm{CDI}_{2}$} & Fuzhou & 0.176 & 0.201 & 0.237 & 0.193 & 0.192 & 0.269 & 0.421 & 0.665 & 0.887 & 0.360 \\
\hline & Putian & 0.088 & 0.150 & 0.199 & 0.166 & 0.245 & 0.360 & 0.701 & 0.733 & 0.931 & 0.397 \\
\hline & Quanzhou & 0.112 & 0.206 & 0.269 & 0.359 & 0.302 & 0.352 & 0.531 & 0.846 & 0.888 & 0.429 \\
\hline & Xiamen & 0.031 & 0.195 & 0.099 & 0.144 & 0.321 & 0.520 & 0.655 & 0.867 & 0.866 & 0.411 \\
\hline & Zhangzhou & 0.048 & 0.117 & 0.130 & 0.209 & 0.280 & 0.327 & 0.575 & 0.770 & 1.010 & 0.385 \\
\hline & Longyan & 0.010 & 0.094 & 0.121 & 0.210 & 0.285 & 0.443 & 0.596 & 0.789 & 1.010 & 0.395 \\
\hline & Sanming & 0.014 & 0.093 & 0.120 & 0.185 & 0.217 & 0.343 & 0.501 & 0.776 & 1.010 & 0.362 \\
\hline & Nanping & 0.042 & 0.157 & 0.093 & 0.174 & 0.271 & 0.347 & 0.630 & 0.866 & 0.966 & 0.394 \\
\hline & Ningde & 0.010 & 0.074 & 0.189 & 0.259 & 0.324 & 0.491 & 0.639 & 0.842 & 1.010 & 0.426 \\
\hline \multirow{9}{*}{$\mathrm{CDI}_{3}$} & Fuzhou & 0.391 & 0.434 & 0.470 & 0.537 & 0.555 & 0.611 & 0.715 & 0.757 & 0.781 & 0.583 \\
\hline & Putian & 0.480 & 0.268 & 0.386 & 0.345 & 0.266 & 0.361 & 0.589 & 0.768 & 0.787 & 0.472 \\
\hline & Quanzhou & 0.286 & 0.312 & 0.413 & 0.338 & 0.429 & 0.545 & 0.684 & 0.802 & 0.842 & 0.517 \\
\hline & Xiamen & 0.343 & 0.386 & 0.327 & 0.420 & 0.449 & 0.503 & 0.625 & 0.707 & 0.722 & 0.498 \\
\hline & Zhangzhou & 0.211 & 0.326 & 0.249 & 0.213 & 0.277 & 0.474 & 0.512 & 0.450 & 0.487 & 0.355 \\
\hline & Longyan & 0.194 & 0.328 & 0.348 & 0.261 & 0.266 & 0.506 & 0.638 & 0.700 & 0.765 & 0.445 \\
\hline & Sanming & 0.231 & 0.217 & 0.307 & 0.419 & 0.467 & 0.688 & 0.803 & 0.887 & 0.928 & 0.550 \\
\hline & Nanping & 0.264 & 0.434 & 0.522 & 0.372 & 0.363 & 0.602 & 0.686 & 0.801 & 0.837 & 0.542 \\
\hline & Ningde & 0.245 & 0.261 & 0.453 & 0.508 & 0.505 & 0.492 & 0.600 & 0.727 & 0.797 & 0.510 \\
\hline \multirow{9}{*}{$\mathrm{C}$} & Fuzhou & 0.459 & 0.837 & 0.962 & 0.919 & 0.907 & 0.939 & 0.963 & 0.994 & 0.997 & 0.886 \\
\hline & Putian & 0.806 & 0.897 & 0.915 & 0.845 & 0.836 & 0.889 & 0.917 & 0.980 & 0.740 & 0.869 \\
\hline & Quanzhou & 0.503 & 0.972 & 0.984 & 0.985 & 0.954 & 0.963 & 0.991 & 0.999 & 0.999 & 0.928 \\
\hline & Xiamen & 0.644 & 0.959 & 0.871 & 0.895 & 0.991 & 0.870 & 0.673 & 0.980 & 0.995 & 0.875 \\
\hline & Zhangzhou & 0.702 & 0.841 & 0.808 & 0.853 & 0.975 & 0.974 & 0.853 & 0.906 & 0.916 & 0.870 \\
\hline & Longyan & 0.537 & 0.796 & 0.808 & 0.835 & 0.846 & 0.993 & 0.991 & 0.979 & 0.983 & 0.863 \\
\hline & Sanming & 0.594 & 0.910 & 0.896 & 0.925 & 0.919 & 0.960 & 0.980 & 0.989 & 0.991 & 0.907 \\
\hline & Nanping & 0.530 & 0.903 & 0.799 & 0.885 & 0.913 & 0.943 & 0.993 & 0.997 & 0.998 & 0.885 \\
\hline & Ningde & 0.529 & 0.874 & 0.923 & 0.963 & 0.980 & 0.998 & 0.999 & 0.993 & 0.994 & 0.918 \\
\hline
\end{tabular}

$\mathrm{CDI}_{1}$ represents the comprehensive development level of the tea industry, $\mathrm{CDI}_{2}$ represents the comprehensive development level of the tourism industry, $\mathrm{CDI}_{3}$ represents the comprehensive development level of the ecological environment, and $\mathrm{C}$ represents the coupling degree.

However, the comprehensive development levels of three sub-systems in the nine cities were heterogeneous, showing different development levels for different cities. In general, 
the average value of the tourism comprehensive development index was less than that of the tea industry and ecological environment in the nine cities from 2011 to 2019. In Putian, Quanzhou, Zhangzhou, Longyan, and Nanping, the average value of the comprehensive development index of the tea industry was higher than that of the tourism industry and ecological environment, indicating that the development level of the tea industry was high in these five cities. The reason for this is that these five cities had a large scale of tea planting and a large number of tea brands. The mean value of the comprehensive development index of the tea industry was lower than that of the tourism industry and ecological environment in Xiamen, mainly as Xiamen is a tourism-oriented service city [63] and its tea development is limited, due to a lack of agricultural arable land; urban leisure agriculture has mainly been developed [64]. Meanwhile, the mean value of the ecological environment comprehensive development index was lower than that of the tea industry and tourism in Zhangzhou, indicating that the development of the tea tourism industry had a negative impact on the ecological environment in this city.

\subsection{Spatiotemporal Evolution Characteristics of Coupling Coordination Degree}

The coordination degree of the tea industry-tourism-ecological environment system in Fujian Province and nine cities was evaluated (see Table 5 and Figure 4). It can be seen that, on the whole, the coordination degree curves of the nine cities presented overlapping characteristics. The coordination degrees of the three sub-systems for the nine cities were close within the same year, and their growth trends and directions were consistent with the overall coupling coordination degree curves of Fujian Province. From 2011 to 2019, the coordination degree of three sub-systems in the nine cities of Fujian Province presented a stepwise progressive coupling coordination trend. From the perspective of specific cities, the coordinated growth rates of Putian and Zhangzhou were relatively slow, while the coordinated growth rates of Quanzhou, Ningde, Nanping, and Sanming were relatively fast. Quanzhou was the first city to enter the high-quality coordination stage; furthermore, compared with the other cities, its average coordination degree over the considered nine years was the highest.

Table 5. Coordination index of the tea industry-tourism-ecological environment systems in various cities in Fujian province from 2011 to 2019.

\begin{tabular}{ccccccccccc}
\hline City & $\mathbf{2 0 1 1}$ & $\mathbf{2 0 1 2}$ & $\mathbf{2 0 1 3}$ & $\mathbf{2 0 1 4}$ & $\mathbf{2 0 1 5}$ & $\mathbf{2 0 1 6}$ & $\mathbf{2 0 1 7}$ & $\mathbf{2 0 1 8}$ & $\mathbf{2 0 1 9}$ & Mean \\
\hline Fuzhou & 0.312 & 0.469 & 0.599 & 0.602 & 0.622 & 0.684 & 0.795 & 0.872 & 0.926 & 0.654 \\
Putian & 0.494 & 0.515 & 0.594 & 0.581 & 0.606 & 0.695 & 0.692 & 0.812 & 0.684 & 0.630 \\
Quanzhou & 0.276 & 0.484 & 0.592 & 0.622 & 0.659 & 0.715 & 0.803 & 0.920 & 0.943 & 0.668 \\
Xiamen & 0.402 & 0.553 & 0.478 & 0.550 & 0.623 & 0.592 & 0.561 & 0.828 & 0.903 & 0.610 \\
Zhangzhou & 0.405 & 0.522 & 0.517 & 0.545 & 0.566 & 0.669 & 0.600 & 0.664 & 0.750 & 0.582 \\
Longyan & 0.278 & 0.506 & 0.548 & 0.581 & 0.625 & 0.667 & 0.754 & 0.804 & 0.889 & 0.628 \\
Sanming & 0.287 & 0.422 & 0.494 & 0.582 & 0.630 & 0.706 & 0.797 & 0.873 & 0.940 & 0.637 \\
Nanping & 0.256 & 0.501 & 0.524 & 0.582 & 0.639 & 0.745 & 0.784 & 0.892 & 0.950 & 0.652 \\
Ningde & 0.263 & 0.411 & 0.539 & 0.612 & 0.664 & 0.711 & 0.790 & 0.855 & 0.958 & 0.645 \\
Fujian & 0.222 & 0.491 & 0.575 & 0.579 & 0.637 & 0.745 & 0.824 & 0.883 & 0.925 & 0.653 \\
\hline
\end{tabular}




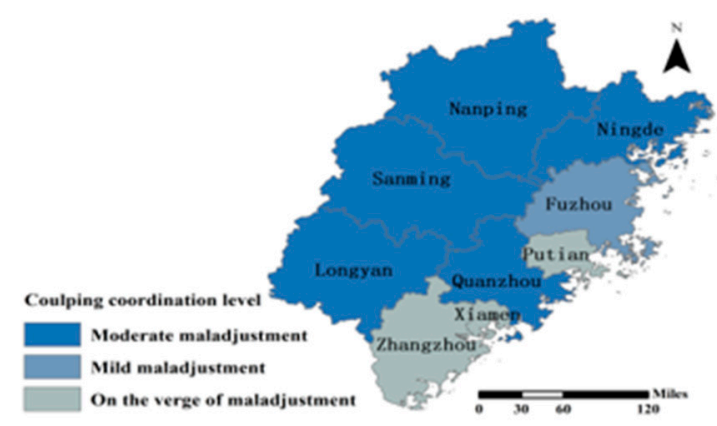

(2011)

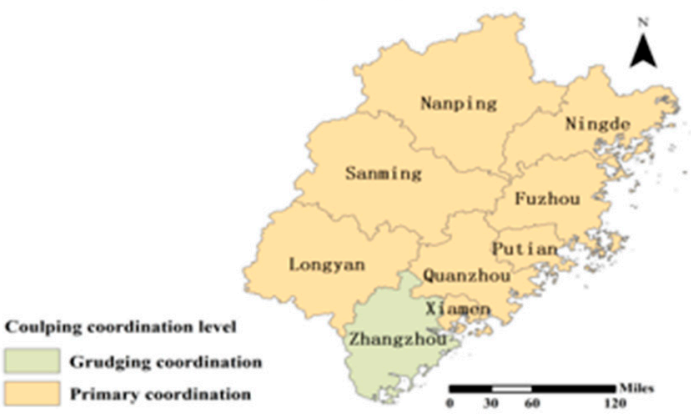

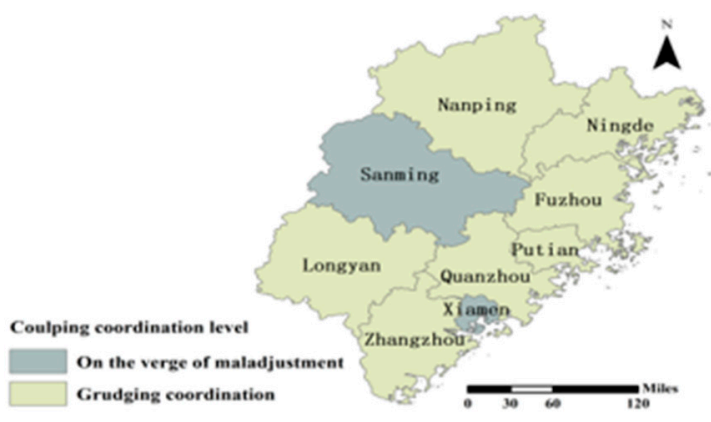

(2013)

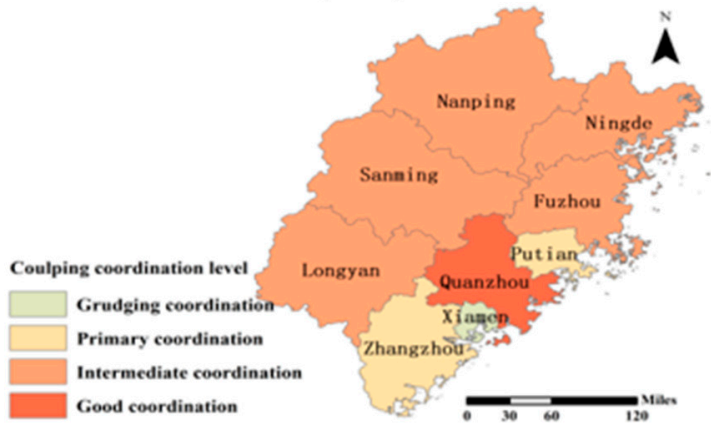

(2017)

(2015)

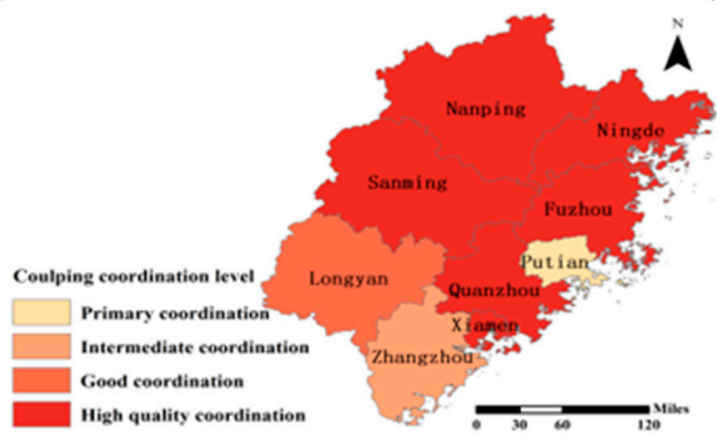

(2019)

Figure 4. Spatial variation in coupling coordination degree of the tea industry-tourism-ecological environment systems for nine cities in Fujian province.

To further depict the spatial and temporal evolution characteristics of the coordination level of the nine cities, we used the ArcGis10.2 software to produce coordination level maps of the nine cities in 2011, 2013, 2015, 2017, and 2019. According to Figure 4, in 2011, five cities were in the moderate maladjustment stage, three cities were on the verge of the maladjustment stage, and Fuzhou was in the mild maladjustment stage. The coordination level of the three systems was still at a relatively low level. From 2013 to 2017, the coordination degree of the nine cities greatly improved. Each city entered the coordinated development stage (good coordination, intermediate coordination, primary coordination, and grudging coordination) in 2017 , from the coordinated transition stage (on the verge of imbalance, grudging coordination) in 2013. In 2017, there were seven cities with coupling coordination higher than 0.7, where Quanzhou had reached a value higher than 0.8 . By 2019, six cities had reached the high-quality coordination stage, where the coordination level of the three systems was high. Overall, over the nine considered years, the coordination degree of the three systems of the nine cities in Fujian Province was greatly improved, and the nine cities moved forward from the imbalance stage to the coordination stage. From a spatial perspective, in 2011, the coordination degree in the south of Fujian Province was higher than that in the north; however, after 2017, the 
coordination degree in the north of Fujian Province was higher than that in the south. The main reason for this is that the rapid industrial development in the south of Fujian led to high carbon emissions; studies have shown that carbon emissions in southern Fujian increased from $74.08 \mathrm{Mt}$ in 2005 to $169.48 \mathrm{Mt}$ in 2017, with an emissions growth rate of $128.75 \%$ [65], which led to the low degree of coupling and coordination in southern Fujian.

\section{Discussion}

At present, global environmental pollution is becoming increasingly serious, and how to achieve the coordination and sustainable development of the economy and the environment is a common problem faced by all countries. The integration of the tea industry and tourism can increase the value of tea, extend the tea industry chain, and promote regional economic development [12]; however, in the practice of tea tourism integration, driven by blindly pursuing economic development, pesticides have been overused in tea planting, in order to increase tea output $[14,15]$. The excessive and disorderly development of tea resources in various destinations has led to ecological damage, and a large number of tourists entering tea gardens and other destinations for sightseeing have exceeded the carrying capacity of the destinations, bringing further burden to the ecological environment. This article quantitatively explored the coupling and coordination relationships among the tea industry, tourism, and the ecological environment, by constructing a coupling coordination model.

Our results further verify the results of existing research. First, regarding the relationship between tourism and the ecological environment, previous research results have shown that there is a significant coupling relationship between tourism and the ecological environment $[57,58]$. Tourism is the main driver of carbon emissions, and its thesis of a "smoke-free industry" has been disproved by most studies [16,17]; as such, the rapid development of tourism will undoubtedly damage the ecological environment [56]. With the development of tea culture tourism, it was also found that the comprehensive development level of tourism exceeds the ecological environment, due to problems such as the rapid development of tourism and the lag of the ecological environment level. The main reason for this is that the increase in tourist arrivals has led to a surge in the demand for transportation, catering, and accommodation, which has brought about a large amount of carbon emissions and the production of sewage; these are some of the reasons for the lagging of the ecological environment [31].

Second, regarding the relationship between the tea industry and the ecological environment, over the past 10 years the tea planting scale in Fujian Province has increased from 190.61 hectares in 2011 to 219.81 hectares in 2019 , with an increase rate of $15.32 \%$, while the tea output has increased from 276,700 tons in 2011 to 439,900 tons in 2019 , with an increase rate of $58.98 \%$ [53], mainly due to the innovations in tea production technology and the improvement of quality in Fujian Province. At the same time, driven by economic interests, tea farmers have used chemical fertilizers and pesticides which, to a certain extent, impose a burden on the ecological environment $[14,15]$. Similarly, in this study, the development level of the tea industry was found to be higher than that of the ecological environment.

Third, regarding the relationship between the tea industry and tourism, the conclusions of this study also verify the results of previous empirical research. Wang analyzed the coupling and coordination of the tea industry and tourism in Fujian Province from 2000 to 2016 and showed that the development level of the tea industry was higher than that of tourism and the ecological environment in Fujian Province, where the coupling coordination degree reached 0.65 [18]. Wang also carried out empirical research and found that the coupling coordination degree of the tea tourism industry in Fujian Province reached intermediate coordination in 2017 [25], which is consistent with the result of this paper. Ways to develop the role of the tea industry and to promote the development of tourism through the tea industry are issues that need to be further considered.

Fourth, regarding the coupling and coordination between the tea industry, tourism, and the ecological environment, our research showed that the coupling and coordination 
degree of the tea industry-tourism-ecological environment system in Fujian Province was spatially heterogenous, where the coupling and coordination degree of cities in the south of Fujian Province was higher than that in the north in 2011, while the coupling and coordination level in the north of Fujian Province was higher than that in the south in 2017; the main reason being that the rapid industrial development in southern Fujian led to high carbon emissions: studies have shown that carbon emissions in southern Fujian increased from 74.08 Mt in 2005 to $169.48 \mathrm{Mt}$ in 2017, with an emissions growth rate of $128.75 \%$ [65]. Therefore, the tourist economy and industrial economy have a restraining effect on the ecological environment [66], eventually leading to the degree of coupling and coordination of these systems being lower than that in northern Fujian.

Finally, Fujian Province has abundant tea resources; how to play the leading role of the tea industry, in terms of tourism, and how to feedback the development of the tea industry through tea tourism integration, are problems that need to be considered and solved in the near future. On the other hand, from 2018 to 2019, the development level of the ecological environment in Fujian Province lagged behind the development level of the tea industry and tourism, indicating that, with the development of tea tourism integration, the ecological environment is in a state of restraint, and the integrated development of the tea tourism industry has broken the threshold of the ecological environment. Therefore, the attention of various departments should be attracted, and effective measures to achieve environmental development level improvements should be introduced.

There are three limitations to this paper: First, we selected only Fujian Province as a case study, in order to analyze the coupling coordination relationship and comprehensive development level among the tea industry, tourism, and the ecological environment, and did not conduct an analysis concerning all 31 provinces of China; as such, the scope of the sample was controlled, which would make our research conclusions unable to be generalized to the whole country. The spatial scope of application of the research conclusion is limited, and the horizontal comparative analysis with other provinces cannot be carried out. Second, some factors may affect the coordinated development of the tea industry, tourism, and the ecological environment, such as economic development level, government policies, industrial structure, and environmental awareness. However, there was no further empirical study on the promotion factors and obstacles of the coupling and coordination relationship among the tea industry, tourism, and the ecological environment; this will also lead to the inability to provide precise countermeasures and concrete operational suggestions for improving the coupling and coordinated development of the tea industry, tourism, and the ecological environment. Third, we attempted to construct an overall evaluation system of the tea industry, tourism, and the ecological environment. Pesticide use indicators and carbon emissions of tourism can be considered key indicators affecting the ecological environment. However, due to limited access to statistical data, these indicators were not included. On the one hand, in the process of future research, building a more perfect and scientific evaluation system is an important direction; as such, some indicators need to be included into the evaluation system, including the utilization rate of chemical fertilizers and pesticides, the growth rate of tea output, and the number of employees of tourism enterprises. On the other hand, the internal influence mechanisms and relationships of the tea industry-tourism-ecological environment system need to be further analyzed and clarified. We can also quantitatively analyze the promoting and hindering factors of the tea industry, tourism, and the ecological environment, through use of the structural equation modelling method. A variety of methods must be used to evaluate the coupling development level of the tea industry-tourism-ecological environment system, and it is necessary to further analyze the spatial and temporal differences between the tea industry, tourism, and the ecological environment from a global perspective. 


\section{Conclusions and Implications}

\subsection{Conclusions}

In this paper, an evaluation index system focused on the tea industry, tourism, and the ecological environment was constructed. The weight coefficient of each indicator was determined using the entropy weight method, and a coupling coordination model was constructed to evaluate the comprehensive development level and coupling coordination degree of the three systems for Fujian province and nine cities. The following conclusions were drawn: First, the research results indicated that the comprehensive development indices of the three systems had an upward trend in Fujian Province from 2011 to 2019, and the overall development level presented a positive development trend. The development level of the tea industry was relatively high, while the development level of the ecological environment was relatively low, in 2018 and 2019. At present, the ecological environment of Fujian Province is lagging behind the development of tourism. This issue needs to be paid attention to by relevant departments. Second, the coordination degree of the three systems changed from moderate maladjustment to high-quality coordination in Fujian province, and the coordination level of the three systems showed a good development trend. Third, the comprehensive development indices of the nine considered cities in Fujian Province presented spatial heterogeneity characteristics, where the ecological environmental development indices of Sanming, Xiamen, Ningde, and Fuzhou were generally higher than those for the tea industry and tourism, while the tea industry development indices of Putian, Quanzhou, Zhangzhou, Longyan, and Nanping were generally higher than those of the tourism industry and ecological environment.

\subsection{Theoretical Contribution}

This research mainly provides theoretical insights in the following two areas: First, the integrated development of the tea industry and tourism is an important part of the coordinated development of the culture-tourism-ecological environment system. However, previous studies have mainly focused on the coupling and coordination relationship between the tea industry and tourism $[12,18]$, ignoring the impact of tea tourism integration on the ecological environment. There is a complex and dynamic relationship between the tea industry, tourism, and the ecological environment; therefore, understanding and dealing with the relationships in the tea industry-tourism-ecological environment system should be the focus of sustainable development. The research on the coupling and coordination relationship between the tea industry, tourism, and the ecological environment presented in this paper serves as a beneficial supplement to the previous research on the coupling relationship between the tea industry and tourism, and further clarifies the important position of the ecological environment in the tea industry.

Second, taking Fujian Province as a typical case, we evaluated the comprehensive development level and coupling coordination degree of the tea industry-tourism-ecological environment system in Fujian Province and nine cities, through the use of the proposed coupling coordination model, the relationships and influence mechanisms within the tea industry-tourism-ecological environment system were explained and analyzed, and the spatial and temporal differences in the development level were fully clarified for the nine considered cities. Previous research on the tea industry and tourism has mainly evaluated the coupling coordination degree from a temporal perspective [25]. In this paper, we not only evaluated the fluctuation trend of the coupling coordination degree of the tea industry, tourism, and the ecological environment from a temporal perspective, but also analyzed the spatial changes in different cities, thus promoting and innovating upon past research perspectives.

\subsection{Practical Implication}

According to the findings of this study, the coupling and coordination of the tea industry, tourism, and the ecological environment can be strengthened in several aspects. Therefore, to promote the sustainable and high-quality development of the tea indus- 
try, tourism, and the ecological environment, the following suggestions and measures are provided:

On the one hand, through the analysis of this article, it can be seen that the ecological environment lagged behind the development of the tea industry and tourism in 2018 and 2019. As such, it is necessary to establish the bottom-line of tea tourism industry development, always considering the ecological environment first, and local governments and enterprises need to firmly adhere to the concept of "green water and green mountains are golden mountains and silver mountains". In the process of developing the tea industry, first, we should adopt advanced production technology, strengthen technological innovation, and eliminate backward tea production methods, in order to reduce environmental pollution. Second, in the process of developing tea culture tourism, the carbon emissions of tourism should be reduced through capital investment and energy-saving production, backward tourism production capacities should be eliminated, tourism pollution control levels should be improved, and the carbon emissions due to tourism should be controlled. At the same time, Fujian Province and all cities need to vigorously develop eco-tea tourism and low-carbon tea tourism, thus promoting the green transformation and upgrading of the tea tourism industry structure, and need to cooperate in capital investment, technology $\mathrm{R} \& \mathrm{D}$, and industrial structure optimization to strengthen environmental protection and environmental governance.

On the other hand, it is better to adopt a variety of methods and means to improve the development level of tea tourism integration. First, tourism companies need to do their best to make up for the shortcomings of tourism development, deeply explore the functional attributes of the tea industry and tea culture, strengthen the deep integration of the tea industry and tourism, and promote the transformation and upgrading of the tourism industry. Second, tourism companies and tea companies should give full play to the advantages of tea planting, output, quality, and brand; extend the upstream and downstream chains of the tea industry; realize the integration of the tea industry with secondary and tertiary industries in breadth, width, and depth; and facilitate the tea industry structural transformation upgrading and realization of functional value. Altogether, these efforts will serve to promote the high-quality development of the tea industry. Finally, the deep integrated development of the tea tourism industry can bring greater economic benefits, and the improvement of economic benefits also provides more funds to invest in environmental infrastructure and environmental pollution control, which is conducive to the improvement of the ecological environment.

Author Contributions: Conceptualization, Z.L. and Q.C.; methodology, Z.L.; validation, Z.L., Q.C. and L.X.; formal analysis, Z.L.; investigation, Z.L.; resources, Q.C.; writing-original draft preparation, Z.L.; writing-review and editing, L.X., Q.C. and Z.L.; visualization, Q.C.; supervision, Q.C.; project administration, Q.C. All authors have read and agreed to the published version of the manuscript.

Funding: This research received no external funding.

Institutional Review Board Statement: Not applicable.

Informed Consent Statement: Not applicable.

Data Availability Statement: The data are contained within the article.

Conflicts of Interest: The authors declare no conflict of interest.

\section{References}

1. Pang, J.; Wei, L. The dynamic mechanism and path of the coupling and coordinated development of characteristic agriculture and tourism: A case study of 18 tea-producing provinces in China. World Agric. 2018, 475, 248-255.

2. Xu, Y.M.; Lu, W.J.; Lv, W.X. An empirical analysis of the impact of China's tea export trade on the development of China's tea industry. Tea 2019, 45, 185-192.

3. Liu, C.L.; Xu, M.; Liu, P.L.; Mu, S.L. Analysis on development and cultivation path of the Chinese tea industry. Res. Sci. 2011, 33, 2376-2385. 
4. Liu, Z.H. Development course and trend of tea deep processing industry in China. J. Tea Sci. 2019, 39, 115-122.

5. Li, J.G.; Wu, S.Q.; Chen, J.X. Challenges and countermeasures of tea safety production in China. Gra. Sci. Technol. Econ. 2020, 45, 143-144.

6. China Tea Marketing Association. Analysis of China's Tea Production, Sales and Import and Export Data in 2020. Available online: https: / / cj.sina.com.cn/articles/view/1850460740/6e4bca4402000rjka?display=0\&retcode=0 (accessed on 5 February 2021).

7. IIMedia. Tea Industry Data Analysis. Available online: https://www.iimedia.cn/c1061/77185.html (accessed on 25 February 2021).

8. Zhang, Y.W.; Gong, Y.X.; Huang, Q.L. "Tea tourism integration" promote the transformation and upgrading of the tea industryTaking Hubei dengcun green tea group as an example. Acta Tea Sin. 2013, 3, 32-36.

9. Ji, J.X.; Lei, G.Q. The convergence development of the tea industry and tourism industry in Anxi county. J. Fujian Agric. Fore. Univ. 2019, 22, 67-76.

10. Shen, X.Z.; Su, Z.C.; Wang, X.F. Research on the types of tea culture resources and the business model. J. Tea Sci. 2015, 35, 299-306.

11. Wu, H.Z.; Yao, Z.Z.; Tian, X.S. Measurement and path analysis of coordinated development of tea tourism integration in Anhui Province. J. Tea Commun. 2019, 46, 345-350.

12. Yi, K.G.; Li, J.Y. Integration and interactive development of tea tourism: Model construction and effect measurement: Based on the empirical study in Zhejiang Province. J. Tea Sci. 2017, 37, 532-540.

13. Lu, S. Effect of tea planting on ecological environment protection. Tea Fujian 2018, 40, 15-16.

14. He, D.C.; Zhan, J.S.; Xie, L.H. Problems, challenges and future of plant disease management: From an ecological point of view. J. Integr. Agric. 2016, 15, 705-715. [CrossRef]

15. Xie, L.H. Plant protection strategy of China in the 21 century. Rev. China Agric. Sci. Technol. 2003, 5, 5-7.

16. Pan, Z.Q.; Liang, B.E. Study on the spatial and temporal heterogeneity of the distribution of carbon emission intensity in tourism industry and it's driving factors-Based on the panel data analysis of 30 provinces (Cities, Districts) from 2005 to 2014 . Hum. Geogr. 2016, 31, 152-158.

17. Tao, Y.G.; Huang, Z.F.; Wu, L.M.; Yu, F.L.; Huang, K. Carbon emission measurement and factor decomposition of regional tourism in Jiangsu Province. Acta Geogr. Sin. 2014, 69, 1438-1448.

18. Wang, G.W. The research on the integration and interaction development of tea industry and tourism industry-Taking eight provinces along the "Miles of Tea Road" in China as an example. J. Tea Sci. 2020, 40, 555-564.

19. Zhang, Y.W.; Gong, Y.X. Tea culture tourism under the background of the low carbon economy. Tour. Res. $2011,3,39-42$.

20. Joseph, E.M. The socio-economic and environmental impacts of tourism development on the Okavango Delta, north-western Botswana. J. Arid. Environ. 2003, 54, 447-467.

21. Ma, Y.F.; Zhang, C.H.; Liu, J.S.; Gao, Y.; Pang, W. Coupling with tourism: A new approach to sustainable development research. Tour. Hosp. Prosp. 2018, 2, 1-19.

22. Liu, J.S.; Ma, Y.F. The evolution and driving mechanism of the supply and demand coupling about tourism flow and destination system based on the genesis and system theory: Taking Xi'an as an example. Geogr. Res. 2017, 36, 1583-1600.

23. Jiang, W.W.; Chen, Z. Empirical Study on the coupling and coordinated development of tea culture industry and tourism industry in Guangdong Province. Acta Tea Sin. 2020, 61, 200-206.

24. Wang, K.L.; Pu, Y.L.; Tang, L.Y. Coupling relationship between tea industry and tourism industry-A case study of Yunnan Province. J. Tea Commun. 2020, 47, 526-532.

25. Wang, X.H. Study on the integrated development of tea industry and tourism industry in Fujian Province. Sci. Technol. Innov. Prod. 2020, 4, 28-31.

26. Qin, X.; Li, X. Evaluate on the decoupling of tourism economic development and ecological environmental stress in China. Sustainability 2021, 13, 2149. [CrossRef]

27. Shu, X.L.; Gao, Y.B.; Zhang, Y.X.; Yang, C.Y. Study on coupling relationship and coordinated development between the tourism industry and ecological civilization city. China Popul. Res. Environ. 2015, 25, 82-90.

28. Fang, Y.L.; Huang, Z.F.; Duan, Z.X.; Wang, K. Study on coupling coordination between tourism development and ecological environment in China. Econ. Geogr. 2013, 33, 195-201.

29. Cheng, H.; Xu, Q.; Guo, Y.Q. Spatiotemporal evolution of coupling and coordinated development of tourism resources development and ecological environment in China. Econ. Geogr. 2019, 39, 233-240.

30. Zhang, W.P. Research on the development path of tea culture tourism based on low-carbon economy. Tea Fujian 2017, 39, 112-113.

31. $\mathrm{Xu}, \mathrm{Q}$. The development strategy of tea culture tourism under the background of low-carbon economy. Tea Fujian 2016, 38, $146-147$.

32. Zhao, J.Y.; Wang, J.X. Study on the evaluation of the integration of tea industry and tourism industry in Xinyang city based on coupling coordination degree model. J. Tea Commun. 2019, 46, 55-60.

33. Yin, J.; Yang, Y.T. The spatial and temporal evolution characteristics of coordinated development of exhibition and tourism in China and its driving factors. Econ. Geogr. 2020, 40, 194-202.

34. Cheng, S.W.; Xu, F.F.; Jie, Z.; Zhang, Y.T. Tourists' attitudes toward tea tourism-A case study in Xinyang, China. J. Travel Tour. Mark. 2010, 27, 211-220. [CrossRef]

35. Jolliffe, L. Tea and Tourism: Tourists, Traditions and Transformations; Channel View Publications: Bristol, UK, 2007; pp. 1-24. 
36. Keunuk, L. A study on agriculture tourism of Gudeuljangnon terraced rice paddies and Jeju batdam agricultural system. J. Assoc. Korean Photo-Geogr. 2015, 25, 37-49. [CrossRef]

37. Wang, J.C.; Zhao, X.H. Development of tea culture tourism in China. China Tea 2005, 27, 22-23.

38. Lin, C.C.; Zhang, W.W.; Liu, Y.F.; Cheng, C.F. Tea culture tourism and tea industry economic development. Chin. Agric. Bull. 2008, 24, 385-388.

39. Gao, F.H.; Yu, L. Preliminary study on the interactive development of Jiujiang tea industry and tourism industry. J. Tea Commun. 2018, 45, 49-51.

40. Zhang, Y. Study on the integrated development of tea and tourism in the context of rural revitalization strategy. J. Sichuan Tour. Univ. 2019, 142, 49-51.

41. Anxi County Statistics Bureau. Anxi County National Economic and Social Development Statistical Bullet in 2019. Available online: http:/ /www.fjax.gov.cn/zwgk/zfxxgkzl/zfxxgkml/tjxx/202004/t20200402_2198969.htm (accessed on 27 March 2021).

42. Guo, M.; Wang, Y. Study on tea tourism integration development in southern Shaanxi, based on coupling model. Acta Agric. Jiangxi 2020, 32, 146-150.

43. Hou, Y.X.; Dai, M. Research on the development of tea and tourism industry integration of minority area from the perspective of region-based tourism: A case study of Longsheng County, Guangxi. Tour. For. 2017, 10, 120-128.

44. Pang, J.; Wei, L. Coupling and coordinated development between tea industry and tourism industry-A case study of Sichuan province. Res. Dev. Mar. 2018, 34, 1577-1581.

45. Zheng, Q.E.; Lei, G.Q. The integration of tertiary industries and the transformation and upgrading of tea industry: Problems, driving forces and paths. Acad. Exch. 2019, 5, 114-123.

46. Zhou, C.; Feng, X.G.; Tang, R. Analysis and prediction of the coordinated development of regional economy-ecological environment-tourism industry coupling-taking provinces and cities along the Yangtze River Economic Belt as examples. Econ. Geogr. 2016, 36, 186-193.

47. Zhong, L.S. A review of "research on the development model of low-carbon tourism industry". Res. Sci. 2020, 42, 407-413.

48. Wang, Q.; Wang, X.; Wang, Q. Requirements of tea growth and development on environmental conditions. Sichuan Agric. Sci. Technol. 2011, 12, 28-29.

49. Liao, W.Y. Current situation and Development Countermeasures of tea garden ecosystem in China. Res. Ecol. Agric. 1998, 6, 73-75.

50. Jiang, F.Y.; Wu, Z.D.; You, Z.M. Value evaluation of tea garden ecosystem services in Fujian Province. Tea Sci. Technol. 2010, 1, 25-27.

51. Ruan, J.Y. Ecological carbon sequestration potential of tea and production technology of low carbon tea. China Tea 2010, 7, 6-9.

52. Qiu, F.T.; Gu, Y.H. The coordinated development mechanism of regional economy and environment-Taking Xuzhou as an example. Econ. Geogr. 2006, 26, 1022-1025.

53. Fujian Statistics Bureau. Statistical Bulletin of National Economic and Social Development of Fujian Province in 2020. Available online: http:/ / xxzx.fujian.gov.cn/jjxx/tjxx/202003/t20200302_5206444.htm (accessed on 27 February 2020).

54. Geng, S.T.; Xie, Y.J. Research on coupling relation between tourism economy and ecological environment of china's sub-provincial cities. Urban Dev. Stud. 2013, 20, 91-97.

55. Gao, S.C. Analysis of the evaluation system about urbanization quality. Areal Res. Dev. 2016, 35, 33-39.

56. Xie, X.; Sun, H.; Gao, J.; Chen, F.; Zhou, C. Spatiotemporal differentiation of coupling and coordination relationship of tourismurbanization-ecological environment system in China's major tourist cities. Sustainability 2021, 13, 5867. [CrossRef]

57. Jiao, N.T.; Zheng, X.M.; Yin, J. Evaluation of coupling coordination degree between tourism economy and ecological environment in the Yellow River Basin and its influencing factors. Res. Dev. Mark. 2020, 36, 591-598.

58. Liu, J.; Li, C.; Tao, J.; Ma, Y.; Wen, X. Spatiotemporal coupling factors and mode of tourism industry, urbanization and ecological environment: A case study of Shaanxi, China. Sustainability 2019, 11, 4923. [CrossRef]

59. Li, X.; Kuang, H.; Hu, Y. Carbon mitigation strategies of port selection and multimodal transport operations-A case study of northeast China. Sustainability 2019, 11, 4877. [CrossRef]

60. Ma, Y.; Li, L.X.; Ren, J. Study on the coordinated development of tourism economy, traffic condition and ecological environment in Shennongiia Forest Region. Econ. Geogr. 2017, 37, 215-220.

61. Li, R. Research on Fujian Province Tourism Economic Efficiency Based on DEA Model. J. Shandong Inst. Agric. Eng. 2019, 36, 47-49.

62. Wang, J.P. Problems and countermeasures in the development of tea culture tourism under the background of low-carbon economy. Tea Fujian 2017, 39, 115-116.

63. Chen, Y.Y.; Zhang, L.Y.; Xie, C.W. A multi-level comparative study on the tourism development level of Xia Zhangquan under the strategy of urbanization. J. Huaqiao Univ. Philos. Soc. Sci. Ed. 2017, 6, 75-87.

64. Ke, F.H.; Lin, S.C. The development status of urban leisure agriculture in Xiamen and countermeasures. J. Par. Sch. Xiamen Spec. Econ. Zones 2018, 2, 31-38.

65. Huang, L.L.; Wang, Y.; Zhang, C.; Huang, Y.M. A spatial-temporal decomposition analysis of $\mathrm{CO}_{2}$ emissions in Fujian Southeast Triangle Region. China Environ. Sci. 2020, 40, 2312-2320.

66. Zou, Z. Analysis on the impact of tourism economic development on ecological environment under the background of Rural Revitalization-Taking Chongqing as an example. For. Econ. 2019, 41, 72-76. 